\title{
Breves ponderações acerca das horas in itinere
}

\author{
Brief considerations about the in itinere hours
}

\author{
RODRIGO INOCENTE SASSO
}

\begin{abstract}
RESUMO
O que é hora in itinere, qual sua finalidade e quais as circunstância em que incidirá no contrato de trabalho? Em um primeiro momento será analisada a legislação pertinente à matéria, visualizando também o entendimento jurisprudencial e doutrinário, com a finalidade de conceituar de defini-la, enquanto elemento da jornada de trabalho. Logo depois, serão estudados os elementos transacionais relativos à jornada itinerária, sob a ótica da autodeterminação coletiva, avaliando a eficácia dispositiva do feito.
\end{abstract}

Palavras-chave: Jornada de trabalho. Horas in itinere. Flexibilização da jornada in itinere.

\section{SUMMARY}

What is in itinere hours, which its purpose and when it will focus on employment contract? At first we will analyze the legislation concerning this matter, also viewing the jurisprudential and doctrinal understanding, in order to define it as an element of the workday. Soon after, the transactional elements relating to in itinere journey, according to collective self-determination will be studied, evaluating the effectiveness of the dispositive.

Keywords: Work journey. In itinere hours. In itinere hours flexibility.

\section{INTRODUÇÃO}

Para tratar de jornada de trabalho, tema que sempre aporta contrariedades na ceara trabalhista, é imprescindível a realização de um estudo amplo, que transcenda a letra fria da lei. Para uma boa investigação, deve-se vagar por entre sociologia até a história, tendo às mãos um coeso subsídio doutrinário, mirando sempre o reflexo jurisprudencial causado pelo tema em apreço.

Com base nestes pressupostos, objetiva-se com este ensaio realizar um estudo analítico quanto às horas in itinere, tendo por meta a execução de relevantes considerações acerca do instituto, que será apresentado de forma dinâmica e integradora, a fim de identificar suas diversas nuanças e reflexos contratuais, de modo a contribuir para o avanço no estudo de suas características.

\section{UMAANÁLISE EPISTEMOLÓGICA DAS HORAS IN ITINERE}

No tocante à conceituação legal de horas de trabalho efetivo, o Brasil, por meio do artigo 4- $\mathrm{da}$ CLT, adotou a teoria do período à disposição do empregador no centro de trabalho, compreendido este pelo "estabelecimento em que o empregado, após o trajeto de sua residência, apresenta-se, correndo daí por diante a sua jornada"."

Entrementes, com a evolução mercadológica nacional, associada à complexidade das relações de trabalho, questões de ordem prática, relacionadas às horas de percurso, mostraram a necessidade de flexibilização do então conceito. Neste contexto evolutivo, cumpre recordar a estrutura sob a qual estavam inseridos os trabalhadores em minas de subsolo, que muito tardavam em chegar a seus postos de trabalho, mais das vezes situados há quilômetros de

\footnotetext{
a Advogado; Graduado em Ciências Jurídicas Sociais pelo Centro Universitário Ritter dos Reis (UNIRITTER) e Universidad Europea de Madrid (UEM). Especializando em Direito e Processo do Trabalho pela Verbo Jurídico. Pesquisador junto ao Grupo de Pesquisa Estado, Processo e Sindicalismo - PPGD/ PUCRS.<sasso.r@hotmail.com>.
} 
profundidade, baixo superfície, trajeto este repetido ao final da jornada diária, recebendo, entretanto, apenas pelas horas efetivamente trabalhadas.

Em situação análoga, encontravam-se os empregados portuários, além dos trabalhadores em alto mar, que muito tempo despendiam a chegar aos respectivos pontos de embarque, ou efetivos postos de trabalho, situações estas que fizeram com que o intérprete buscasse uma elasticidade no entendimento do caput do artigo $4^{\circ}$ da CLT $^{2}$.

Uma vez reconhecida a necessidade de proteção ao trabalhador, em especial no que tange o cômputo do tempo gasto no percurso casa-trabalho, o próximo passo seria marcado pela influência jurisprudencial, sacramentada pela edição da Súmula 90 do TST, no ano de 1978, "que considerou razoável a contagem do tempo gasto pelo empregado, se o trajeto já não estivesse mais dentro dos limites corriqueiros do transporte coletivo de uma cidade"s, in verbis:

TST SÚMULA 90 - Condução Fornecida pelo Empregador - Jornada de Trabalho.

I - O tempo despendido pelo empregado, em condução fornecida pelo empregador, até o local de trabalho de difícil acesso ou não servido por transporte regular público, e para o seu retorno, é computável na jornada de trabalho

II - A incompatibilidade entre os horários de início e término da jornada do empregado e os do transporte público regular é circunstância que também gera o direito às horas 'in itinere'.

III - A mera insuficiência de transporte público não enseja o pagamento de horas 'in itinere'.

IV - Se houver transporte público regular em parte do trajeto percorrido em condução da empresa, as horas 'in itinere' remuneradas limitamse ao trecho não alcançado pelo transporte público.

$\mathrm{V}$ - Considerando que as horas 'in itinere' são computáveis na jornada de trabalho, o tempo que extrapola a jornada legal é considerado como extraordinário e sobre ele deve incidir o adicional respectivo. ${ }^{4}$

Recepcionando os termos jurisprudenciais, definiu o legislador pela inserção do parágrafo $2^{\circ}$ ao artigo 58 da CLT, através da Lei 10.243/01, determinando que "O tempo despendido pelo empregado até o local de trabalho e para o seu retorno, por qualquer meio de transporte, não será computado na jornada de trabalho, salvo quando, tratando-se de local de difícil acesso ou não servido por transporte público, o empregador fornecer a condução"s.

Sob guarida jurisprudencial, a edição do art. 58 da CLT representa expressivo marco legislativo, ao reconhecer, enquanto garantia laboral, o cômputo à jornada de trabalho do tempo gasto pelo trabalhador para chegar ao posto de trabalho incrustado em local de difícil acesso, incidindo, sobre este período, todos os reflexos contratuais. Entretanto, tendo em vista a inexistência de padrões objetivos, definir quanto à subsunção desta norma ao plano fático tem sido tarefa árdua no cotidiano trabalhista, considerando as lacunas semânticas que circundam o instituto, sobretudo no que diz respeito à sua interpretação e aplicação, principal enfoque do presente estudo.

\section{TERMINOLOGIA E CONCEITO}

Do Latim, itinere nos remete ao conceito de caminho, percurso, rota ou via. Na doutrina jus laboralista, inúmeras são as expressões utilizadas para intitular o período gasto pelo trabalhador no trajeto até o local de trabalho com difícil acesso, em condução fornecida pelo empregador.

Jornada itinerária, trajeto de ida e volta, horas de percurso, transporte, trajeto, in itinere ou de itinerário, são nomenclaturas conceitualmente vinculadas às horas "gastas no trajeto de ida e volta até o local de trabalho de difícil acesso, ou não servido por transporte público regular, em meio de transporte fornecido pelo empregador, as quais são computadas na jornada de trabalho"6.

Da leitura do referido conceito, depreende-se a necessária existência de dois elementos essências para a caracterização das horas in itinere, sejam eles: i) que o local da prestação de serviços esteja em lugar de difícil acesso, ou não seja servido pelos meios normais de transporte público; ii) que o empregador forneça, com meios próprios, a condução 7 .

Passemos, então, à análise um a um destes requisitos.

\subsection{Local de difícil acesso}

Conforme dispões o item I da Súmula 90 do TST, bem como o $\S 2^{\circ}$ do artigo 58 da CLT, é requisito intrínseco ao cômputo da hora in itinere que o local da prestação de trabalho seja reconhecido como de difícil acesso, transito ou chegada, elemento este dotado de certo valor subjetivo. Difícil acesso, nas palavras de Silvânia Beitum, "é o que se caracteriza por ser um caminho, uma entrada ou passagem, que exige um esforço acima do normal para se atingir"».

Muitas empresas, ao definir seu local de instalação, levam em consideração fatores como a proximidade de sua matéria prima, áreas com isenção de impostos, além de outros elementos que instigam os empresários a distanciarem-se dos centros urbanos onde, por 
decorrência lógica, a mão de obra é escassa e o transporte público é insatisfatório.

Russomano Neto recorda que, como incentivo à contratação de operários, as empresas disponibilizam transporte em meio de condução própria, ou terceirizada, o que pode parecer, em um primeiro momento, benefício concedido ao trabalhador, "embora a real benesse se encontre em favor das empresas, que optam por se instalarem em locais de difícil acesso, pois assim gozam de suficiente demanda de mão de obra sem qualquer percalço ou dificuldade desta natureza" $"$.

Deste modo, não pode o empregado arcar com as horas despendidas para chegar ao centro de trabalho com difícil acesso, uma vez que esta situação decorre, unicamente, do interesse do empregador, fazendo jus o operário à percepção das horas in itinere. Nestes termos fixou-se o entendimento do TST, reconhecendo, através da Súmula 90, que "o tempo gasto pelo obreiro na condução disponibilizada pelo empregador, quando em trajeto de difícil acesso ou não servido por transporte publico regular, seria espécie de tempo à disposição, sob poder diretivo patronal, sendo computável na jornada de trabalho" 10 .

Observe-se que, com a edição do sumulado, o conceito subordinatório clássico sofre verdadeira mutação, passando a surtir efeitos para além do tempo à disposição do empregador no centro de trabalho. $\mathrm{O}$ enquadramento como jornada de trabalho do tempo despendido pelo trabalhador para alcançar o local de trabalho com difícil acesso, nada mais é do que a extensão do controle patronal, abrangendo o período in itinere, principalmente se o meio de transporte for pelo empregador propiciado, ambiente onde valerão as suas regras, ainda que meramente comportamentais, devendo os trabalhadores obediência integral.

Neste sentido, enaltece o presente estudo a análise da Orientação Jurisprudencial Transitória de no 36 da SBDI-I do TST, que apresenta a seguinte redação:

HORAS 'IN ITINERE'. TEMPO GASTO ENTRE A PORTARIA DA EMPRESA E O LOCAL DO SERVIÇO. DEVIDA. AÇOMINAS. Configura-se como hora in itinere o tempo gasto pelo obreiro para alcançar seu local de trabalho a partir da portaria da Açominas.

Essencialmente, a OJT-36 da SBDI-I do TST passa a reconhecer como in itinere o tempo despendido para trajetos no âmbito interno empresarial, como o percurso "portaria-posto de serviço", desde que este represente trecho de longas dimensões, com transporte fornecido pelo empregador.

De acordo com Russomano Neto, "verifica-se que o entendimento de o que seja horas in itinere, anteriormente delimitado somente a trechos públicos, foi ampliado para abarcar também aquele trecho em via particular, cujo proprietário é o empregador"11.

No que tange à classificação do local de trabalho como sítio de difícil acesso, parece haver dois elementos geradores de tal condição, sendo um deles a inexistência de transporte público regular, objetivamente aferível, cumulado com uma distância considerável a ser percorrida, ponto este que abarca divergências dado o seu caráter subjetivo.

$\mathrm{Na}$ Espanha, artigo 2을 da antiga Ordem de 10 de fevereiro de $1958^{12}$, expedida pelo Ministério do Trabalho, havia definido que aquele local de trabalho que estivesse há mais de $02 \mathrm{~km}$ (dois quilômetros) do perímetro urbano seria classificado como local de difícil acesso, tendo direito o empregado à integração do tempo de percurso à jornada normal de trabalho.

De fato, a Lei acaba por objetivar o conceito de difícil acesso, o que põe fim à dúvida classificatória. Entretanto, não parece ser este um critério razoável a ser utilizado, uma vez que a condição de estar distante do centro urbano não constitui sinônimo de inexistência de transporte público regular.

Ricardo Almeida, ao falar da subjetividade do local de difícil acesso, esclarece ser perfeitamente possível a "existência de transporte público à proximidade de determinadas localidades que não tiram a condição de difícil acesso, de forma que o fornecimento de transporte pelo empregador caracterizaria o direito da chamada hora in itinere por parte do empregado"13. Por fim, posiciona-se o autor pela impossibilidade de "haver uma descrição específica quando a uma distância mínima ou máxima entre a condução pública e o local da prestação de serviço para se caracterizar o malfadado local de difícil acesso"14.

Interessante se faz mencionar o estudo publicado em março de 2013 pelo Instituto de Pesquisa Econômica Aplicado (Ipea), que avaliou o tempo de deslocamento casa-trabalho nas principais cidades do mundo. No município de São Paulo, por exemplo, o tempo médio do percurso fica na base de 43 minutos $^{15}$.

Dentro deste cenário, constatamos que a caracterização do local de difícil acesso tampouco se vincula simplesmente ao tempo do deslocamento absoluto, sendo perfeitamente possível que a empresa encontrese afastada de regiões urbanas centrais, mas com primorosa prestação de transporte público.

Concluímos assim que, de difícil acesso é o local de trabalho que, independente da distância do centro urbano, encontra-se afastado do perímetro coberto por transporte público regular, o que caracteriza, per si, um ônus ao trabalhador pelo extraordinário esforço em atingi-lo. 


\subsection{Transporte público regular}

Outro requisito necessário à perfectibilização das horas in itinere é a inexistência de transporte público, considerado todo e qualquer meio de transporte oferecido à população, pelos órgãos públicos competentes, com regular periodicidade.

Neste sentido, nos auxiliam as palavras de Silva e Martins, ao explicarem que "para que se afaste o direito às horas in itinere, é necessário que o trajeto seja servido por transporte público constante, diário, de modo que ao trabalhador seja assegurado meio de locomover-se até o local de trabalho em todos os dias de labor" $"$.

Tal requisito, a priori, nos parece objetivamente claro e facilmente aferível, do ponto de vista que gozam as linhas de transporte público rotas e itinerários previamente definidos e estáveis. Entretanto, algumas situações vinculantes merecem margem de estudo, como veremos agora:

a) Incompatibilidade entre a jornada de trabalho e prestação de transporte público: como prevê o item II da Súmula 90 do TST, comprovada a incompatibilidade entre os horários de início e termino da jornada de trabalho com o transporte público regularmente oferecido, faz jus o trabalhador ao pagamento das horas in itinere.

b) Insuficiência de transporte público: já o item III do mesmo enunciado nega a jornada itinerária, quando constatada mera insuficiência do transporte público oferecido, "já que, muito embora a frota oferecida pelo órgão público seja escassa, considera-se que o trajeto não é de difícil acesso por contar com serviço de condução coletiva"17.

c) Condução fornecida pelo empregador, paralelamente ao transporte público: em tal situação não há de se falar em percepção de horas in itinere, uma vez que a inexistência de transporte público é requisito inexorável à constituição fática do instituto. Trata-se de mera vantagem oferecida ao trabalhador, que poderá ser enquadrada como salário utilidade, sem perder essa condição, independentemente de qualquer desconto legal efetuado ${ }^{18}$.

d) Trajeto parcialmente servido por transporte público: fez constar o TST, através do item IV da Súmula 90, a condição de que "se houver transporte público regular em parte do trajeto percorrido em condução da empresa, as horas in itinere remuneradas limitam-se ao trecho não alcançado pelo transporte público". e) Horas de embarque: constituem horas de embarque o período em que o trabalhador aguarda pela chegada do transporte oferecido pelo empregador que, de modo algum, deverá ser integrado à jornada de trabalho. Neste sentindo, recorremos à interpretação teleológica do enunciado na Súmula 90 do TST, que condiciona a noção de hora in itinere ao exercício direto de subordinação empresarial, o que não ocorre no momento em que o empregado espera a condução no ponto ajustado.

Ainda que conte com certas especificidades, conceituar transporte público regular não é das tarefas mais difíceis, justamente pela objetividade com que se constrói sua definição. Havendo, portanto, transporte público diário e constante, sendo assegurado ao trabalhador o meio de locomover-se ao seu respectivo local de trabalho, sempre que necessário, não há de se falar em jornada itinerária.

\subsection{Transporte fornecido pelo empregador}

Outro requisito necessário à caracterização do benefício denominado horas in itinere é a concessão de transporte por parte do empregador, independente do meio ou forma por ele elegida.

Tal exigência encontra fulcro nos ditames da Súmula 90 do TST, em seu primeiro item, além do $\S 2^{\circ}$ do artigo 58 da CLT, que remete ao sentido de condição sinequa non à configuração da hora in itinere o fornecimento da condução pelo empregador.

Por decorrência lógica, compreende-se que "se o empregado utilizar qualquer meio de transporte para chegar ao local de trabalho, não fornecido pelo empregado, não terá direito ao cômputo das horas gastas no percurso à sua jornada de trabalho, mesmo que em local de difícil acesso"19.

Sem embargo, observa-se que este entendimento vem sendo questionado, uma vez que, identificado o local de trabalho com difícil acesso, por que haveria o empregado que escolhe outro meio de condução - que não o da empresa -, deveria ser prejudicado? Para fins de hora in itinere, o que, objetivamente, difere o trabalhador que se desloca em condução própria, daquele que faz uso de veículo fornecido pelo empregador?

Com base nisto, desponta um moderno entendimento jurisprudencial, reconhecendo jornada itinerária ao trabalhador que utilize de veículo particular para se locomover ao local de trabalho situado em difícil acesso. Tais decisões, sobretudo do TRT 12 - Santa Catarina, reconhecem o direito ao cômputo da hora in itinere, independentemente do veículo utilizado pelo 
trabalhador, sob a égide do princípio da equidade. De acordo com os julgados, não existiria razão para distinguir aquele que está - ou não - em veículo do empregador, havendo jornada itinerária sempre que constatado o difícil acesso, ônus que deve suportar o empregador:

HORAS IN ITINERE. UTILIZAÇÃO DE VEÍCULO PRÓPRIO. PERSISTÊNCIA DO DIREITO DO EMPREGADO. O pagamento das horas in itinere está relacionado com o interesse do empregador em viabilizar o seu empreendimento em local de difícil acesso ou não servido por transporte regular público. $\mathrm{O}$ fato de o trabalhador lançar mão de veículo próprio para chegar ao seu local de trabalho apenas beneficia o empregador, que, além de não necessitar disponibilizar transporte ao empregado, somente tem a obrigação de retribuir o tempo efetivamente gasto no seu deslocamento, não raras vezes muito menor do que aquele que seria efetivado pelo meio de transporte disponibilizado à generalidade dos trabalhadores da empresa. $\mathrm{O}$ direito se torna ainda mais inafastável se o trabalhador se utiliza de veículo próprio para chegar ao seu local de trabalho por pura necessidade, quando o empregador nem sequer lhe disponibiliza transporte. - Juíza Águeda Maria L. Pereira - Publicado no TRTSC/DOE em 13.03.2009. Processo: №: 014542006-053-12-00-1)

HORAS IN ITINERE. PRINCÍPIO DA IGUALDADE. Para chegar no horário ao seu local de trabalho, a maioria dos trabalhadores gasta considerável tempo no trajeto, deslocando-se por conta própria, sem cogitar o cômputo daquele tempo como à disposição da empresa para efeito de remuneração. Assim, tratar diferente o empregado que se desloca ao serviço em condução fornecida pelo empregador significa ferir de morte o princípio da igualdade consagrado na Constituição Federal, sob o qual se deve curvar esta Justiça. (TRT 12 ${ }^{\mathrm{a}}$ Região, Processo no 00070-2008-025-12-00-4)

Apesar de a jurisprudência concentrar-se na jornada itinerária realizada em veículo motorizado, cabe mencionar as formas de deslocamento alternativo, que não merecem fuga no apreço. Assim sendo, acredita-se que também faz jus à hora in itinere o trabalhador que utilize de qualquer veículo de tração humana, como a bicicleta, ou mesmo animal, a exemplo do cavalo, sempre que utilizados para aceder ao posto de trabalho em local de difícil acesso. Ademais, não merece o mesmo benefício aquele que tal trajeto percorre pela força das próprias pernas?

\section{FLEXIBILIZAÇÃO DAS HORAS IN ITINERE}

Com a promulgação Constitucional de 1988, o legislador originário possibilitou a flexibilização de alguns direitos trabalhistas, sobretudo no que diz respeito à jornada de trabalho e o salário, mediante negociação coletiva, reconhecendo, portanto, a validade deste instrumento enquanto elemento transacional.

Objetivamos neste capítulo, avaliar a possibilidade de aplicação do artigo $7^{\circ}$ da Constituição, em especial dos incisos VI, XIII e XIV, no que tangencia a flexibilização das horas in itinere, em consonância com o inciso XXVI do mesmo título.

\subsection{O Afrouxamento do Direito às Horas in Itinere por Instrumento de Negociação Coletiva}

Ao avaliarmos a construção fática das horas in itinere, verificamos que esta se perfaz pela união de dois importantes elementos inerentes à relação de emprego: jornada de trabalho, uma vez que constituí tempo à disposição do empregador, e salário, dado ao seu aspecto remuneratório.

Conforme enunciado pelo artigo $7^{\circ}$ da Constituição, incisos VI, XIII e XIV, não restam dúvidas quanto à validade das negociações coletivas, no que diz respeito à flexibilização da jornada de trabalho e do salário do trabalhador. Entrementes, divergentes pontos dogmáticos e jurisprudenciais se apresentam quando suscitada a aplicabilidade do artigo 7으, inciso XXVI, no que diz respeito às horas in itinere.

De um lado, teremos uma corrente doutrinária ${ }^{20}$ que desconhece como válida a cláusula convencional coletiva que dispõe sobre o direito às horas in itinere, considerando a inexistência de previsão normativa específica, alegando também que os direitos trabalhistas constituem garantias mínimas, de caráter cogente e imperativo.

Doutro modo, norteados por princípios do Direito Sindical e da parcela dispositiva do Direito do Trabalho, teremos doutrinadores posicionando-se pela validade das clausulas convencionais, em se tratando de horas de percurso, sob a chancela da autodeterminação coletiva.

Primeiramente, no que tange o estudo da flexibilização das horas de percurso, necessária se faz a análise de dois instrumentos que viabilizam a negociação deste direito: o da supressão e o da pré-fixação.

Entende-se por pré-fixação o ajuste prévio do número de horas in itinere a serem pagas de forma fixa. Esta possibilidade surgiu no ordenamento jurídico brasileiro com o intuito de proteger os trabalhadores rurais, uma vez que sem a pré-fixação assentada em 
convenção coletiva, dificilmente os empregadores rurais pagariam espontaneamente a hora de transporte $^{21}$.

Nesta mesma esteira, Homero Batista reforça que "estipular simplesmente a média de trajeto gasto, no ambiente desprovido por transporte público, é medida razoável, que atende até mesmo aos anseios da segurança jurídica", uma vez que, em zonas afastadas dos centros urbanos, torna-se difícil o controle preciso do tempo despendido pelo trabalhador para chegar ao seu local de trabalho ${ }^{22}$.

Sob o prisma do direito individual do trabalho, envolto por garantias e fundamentos sociais protecionistas, pode parecer "injusta" a norma coletiva que pré-fixa a hora de percurso, ao passo que tende à redução de direitos do trabalhador. Entretanto, considerando a teoria do conglobamento ou incidibilidade, onde as normas trabalhistas devem ser interpretadas no seu conjunto, e não apenas no que é mais - ou menos - favorável, este sentido de "injustiça" se esvai.

Em que pese os instrumentos coletivos possam opor restrições a determinados direitos trabalhistas, trarão, por outro lado, vantagens específicas a certa categoria, de acordo com as necessidades dessa classe operária. Derrogar cláusula coletiva simplesmente sob argumentos ideológicos e paternalistas, privilegiando o individual em detrimento ao difuso, constitui grave ameaça à autodeterminação coletiva, princípio basilar do Direito Coletivo do Trabalho.

Como alerta Waldir Resende de Lara ${ }^{23}$, é importante que a jurisprudência trabalhista transcenda os limites do individual e passe a pensar em termos mais coletivos, mais abrangentes, sob pena de um empobrecimento da força coletiva, um enfraquecimento da barganha sindical.

Em exame à jurisprudência colacionada pelo Tribunal Superior do Trabalho, concluímos pela necessidade de amparo jurisdicional das ponderações aqui narradas, senão vejamos:

Em acórdão publicado pela $6^{\mathrm{a}}$ Turma do Egrégio Tribunal, considera-se válida a cláusula coletiva que delimita o tempo a ser remunerado a título de horas de percurso, independentemente do tempo real gasto no trajeto:

HORAS IN ITINERE. LIMITAÇÃO MEDIANTE NORMACOLETIVA. POSSIBILIDADE. É válida a norma coletiva que delimita o tempo a ser remunerado a título de horas in itinere, independentemente do tempo real gasto no trajeto, em razão do reconhecimento das convenções e acordos coletivos do trabalho, prestigiados no artigo 7º, inciso XXVI, da Constituição Federal. Precedentes. Recurso de revista não conhecido. (RR - 660-71.2010.5.09.0000, Relator Ministro: Augusto César Leite de Carvalho, Data de julgamento: 23/05/2012, 6- Turma, Data de publicação: 01/06/2012)

Entendimento distinto é o entendimento da $7 \underline{a}$ Turma do mesmo Tribunal, que determinou a nulidade de norma coletiva que reduziu de três horas, para uma hora de percurso remunerado:

RECURSO DE REVISTA. HORAS - IN ITINERE -. AJUSTE POR NORMA COLETIVA. INVALIDADE. Com a edição da Lei no ${ }^{-10.243 /}$ 2001, que acrescentou o $\S 2^{\mathrm{o}}$ ao artigo 58 da CLT, $\mathrm{o}$ direito às horas in itinere passou a ser assegurado por norma de ordem pública, cogente, não podendo prevalecer a supressão do direito por meio de negociação coletiva, sob pena de se sonegar direito indisponível do trabalhador. No mesmo sentido, encontra-se a norma coletiva que pretende descaracterizar a natureza jurídica salarial do período em questão. Dessa forma, a despeito de a Constituição Federal de 1988, em seu artigo $7^{\circ}$, inciso XXVI, prestigiar e valorizar a negociação coletiva, não se pode subtrair direito do empregado assegurado em norma cogente. No caso, a norma coletiva além de reduzir de três horas, para uma hora de percurso, lhe conferiu natureza indenizatória e excluiu a remuneração como hora extra, desvirtuando, por completo, o citado instituto jurídico, que certamente tem caráter salarial. Precedentes desta Corte Superior. Recurso de revista de que não se conhece. (...) (RR - 5890002.2009.5.09.0093, Relator Ministro: Pedro Paulo Manus, Data de julgamento: 30/05/2012, 7aㅡ Turma, Data de publicação: 01/06/2012)

Observe-se que, em se tratando de pré-fixação de jornada itinerária remunerada, não há um consenso jurisprudencial quanto à sua validade, o que denota considerável insegurança jurídica.

Supressão das horas in itinere, por sua vez, constitui cláusula normativa que prevê a renúncia integral antecipada do benefício, prática esta que vêm sido rechaçada pela doutrina e jurisprudência, vez que apresenta indubitável caráter fraudulento à relação de emprego, justamente por ultrapassarem as razões e proporcionalidades do direito transacional. Milton de Moura França, ao discorrer sobre o tema, afirma ser ineficaz a cláusula em acordo ou convenção coletiva, que estabeleça a renúncia antecipada ao direito sobre as horas in itinere, enquanto flagrante desrespeito a preceitos imperativos, de ordem pública e de conteúdo 
protecionista, garantidos pela CLT através dos artigos $9^{\circ}$ e $444^{24}$. balho:

Assim compreende o Tribunal Superior do Tra-

HORAS IN ITINERE. SUPRESSÃO MEDIANTE ACORDO COLETIVO. IMPOSSIBILIDADE. Com a edição da Lei no 10.243/2001, que acrescentou o $\S 2^{\circ}$ ao artigo 58 da CLT, o direito às horas in itinere passou a ser assegurado por norma de ordem pública, não podendo prevalecer a supressão do direito por norma coletiva, sob pena de se restringir direito indisponível do trabalhador. Assim, mesmo que o artigo $7^{\circ}$, inciso XXVI, prestigie e valorize a negociação coletiva, todavia, não se pode subtrair direito do empregado assegurado por lei. Recurso de revista conhecido por violação do art. $7^{\circ}, \mathrm{XXVI}$ da $\mathrm{CF}$ e provido. (RR no 1031-17.2011.5.24.0086, 3ํㅡㄹ Turma do TST, Rel. Alexandre de Souza Agra Belmonte. Unânime, DEJT 31.01.2013).

Ainda que haja certa divergência, em geral, doutrina e jurisprudência se dirigem ao reconhecimento da flexibilização quanto à remuneração das horas itinerárias, desde que coletivamente ajustada, resguardados critérios razoáveis e proporcionais de transação, jamais com o objetivo de suprimir tal direito, mas ajustá-lo a uma condição exequível, garantindo a plena eficácia ao instituo.

\subsection{A Lei Complementar 123/2006}

Considerável precedente normativo foi a Lei Complementar $123 / 2006$, que instituiu o parágrafo $3^{\circ}$ ao artigo 58 da CLT, possibilitando às microempresas e empresas de pequeno porte executar negociações relativas às horas in itinere, pré-fixando-as através de acordo ou convenção coletiva.

Conforme esclarecem Silva e Martins, em dissertação sobre o tratamento brasileiro das horas in itinere, "a lei passou a reconhecer a possibilidade de prefixação do tempo gasto no trajeto até o local de trabalho, ainda que com referência às microempresas e empresas de pequeno porte, o que, a nosso ver, não impede a aplicação aos demais empregadores, com fulcro na analogia e ante a inexistência de motivos relevantes para o tratamento diferenciado deste caso" 25 .

A adição do parágrafo $3^{\circ}$, ao artigo 58 da CLT, representa mais uma conquista à autodeterminação coletiva, resguardando efetivamente a autonomia sindical em letra de lei, mesmo que limitada às horas in itinere do empregado em micro e pequena empresa. Ao que tudo indica, este dispositivo legal insurge no direito brasileiro com o objetivo de dar margem às negociações coletivas em matéria de jornada itinerária, o que, literalmente, estaria restrito aos tipos empresariais previstos na Lei 123/2006, mas também aplicável aos demais profissionais, considerando os princípios isonômicos que garantem o Direito do Trabalho.

\section{CONSIDERAÇÕES FINAIS}

Suscitada pelo poder judiciário, ratificada pelo legislativo, a matéria concernente às horas in itinere ainda causa muito estranhamento aos operadores do Direito, uma vez que tangencia questões de ordem subjetiva, vinculadas à sua interpretação e forma de aplicação.

De um modo geral, verificou-se que sempre que houver condução fornecida pelo empregador, para que o trabalhador acesse local de difícil acesso, não servido por transporte público regular, será a jornada itinerária computada como se trabalho fosse, independentemente de eventual cobrança do transporte por meio do empregador.

Entrementes, doutrina e jurisprudência vêm questionando tais conceitos, sobretudo quanto à possibilidade de adequação do meio de transporte, não importando mais a sua fonte, mas a pura existência do local com difícil acesso, somado ao deslocamento forçoso por parte do trabalhador.

Dentre as flexibilizações inerentes ao instituto, encontra-se a discussão quanto a sua possível préfixação, reconhecida pela maioria da doutrina e jurisprudência, desde que respeitados os parâmetros concessivos, expressados através de negociação coletiva, sem legitimidade para renunciar ao direito. Neste sentido, um grande avanço foi a edição da Lei Complementar 123/2006, legalizando a disposição quanto às horas in itinere às micro e pequenas empresas, quando realizadas através de contrato coletivo, o que parece perfeitamente aplicável aos demais trabalhadores, frente ao princípio da isonomia profissional.

\section{REFERENCIAS}

ALMEIDA, Amador Paes de. CLT comentada. 6. ed. São Paulo: Saraiva, 2009.

ALMEIDA, Ricardo. A construção civil e as horas "in itinere". Jornal Trabalhista Consulex, Brasília, v. 28, n. 1387, p. 11, 08 ago. 2011.

BEITUM, Silvana Marcelo. Das Horas in Itinere. FADAP Revista Jurídica, Tupã, v. 1, n. 3, p. 53-80, dez. 2000.

BRASIL. Constituição (1988). Constituição da República Federativa do Brasil. Brasília, DF, 5 de outubro de 1988. Disponível em: <http://www.planalto.gov.br/ccivil_03/constituicao/ constituicao.htm>. Acesso em: 13 maio 2013. 
BRASIL. Decreto-Lei no 5.452, de $1^{\circ}$ de maio de 1943. Consolidação das Leis do Trabalho. Brasília, DF, 9 de agosto de 1943. Disponível em: <http://www.planalto.gov.br/ccivil_03/decreto-lei/ del5452.htm>. Acesso em: 13 maio 2013.

BRASIL. Lei Complementar n⿳⼈ㅡㄹ 123, de 14 de dezembro de 2006. Institui o Estatuto Nacional da Microempresa e da Empresa de Pequeno Porte; altera dispositivos das Leis no 8.212 e 8.213, ambas de 24 de julho de 1991, da Consolidação das Leis do TrabalhoCLT, aprovada pelo Decreto-Lei no 5.452, de $1^{\circ}$ de maio de 1943 , da Lei no 10.189, de 14 de fevereiro de 2001, da Lei Complementar $\mathrm{n}^{\mathrm{o}}$ 63, de 11 de janeiro de 1990; e revoga as Leis $\mathrm{n}^{\mathrm{O}}$ 9.317, de 5 de dezembro de 1996, e 9.841, de 5 de outubro de 1999. Diário Oficial da República Federativa do Brasil. Brasília, DF, 15 dez. 2006. Disponível em: <http://www.planalto.gov.br/ccivil_03/leis/ lcp/lcp123.htm>. Acesso em: 13 maio 2013.

FRANÇA, Milton de Moura. Renúncia de direito as horas "in itinere" prevista em acordo coletivo: ineficácia. Genesis: Revista de Direito do Trabalho, Curitiba, v. 4, n. 19, p. 31-32, jul. 1994.

INSTITUTO DE PESQUISA ECONÔMICA APLICADA. Tempo de deslocamento casa-trabalho no Brasil (1992-2009): diferenças entre regiões metropolitanas, níveis de renda e sexo. Disponível em: <http://www.ipea.gov.br/portal/index.php?option=com content\&view $=$ article $\& i d=16966>$. Acesso em: 02 maio 2013.
LARA, Waldir de R. Prefixação de horas in itinere e flexibilização de direitos: breves considerações. Revista do Tribunal Regional do Trabalho da 15 $5^{\underline{a}}$ Região, Campinas, n. 4, p. 90-92, jan.-jun.

NASCIMENTO, Amauri Mascaro. Iniciação ao direito do trabalho. 34. ed. São Paulo: LTr, 2009.

RUSSOMANO NETO, Mozart Victor. Horas in itinere: caracterização, trajeto interno, portão de acesso-local demarcação do ponto: breve análise ao entendimento do TST quanto à aplicação analógica da orientação jurisprudencial transitória $\mathrm{n}$ - 36 da SDI-1. LTr Suplemento Trabalhista, São Paulo, v. 44, n. 103, p. 515-516, 2008.

SILVA, Fábio Luiz Pereira da; MARTINS, Rafael Tárrega. Horas "in itinere": tratamento no Brasil e na Espanha. Revista Nacional de Direito do Trabalho, Ribeirão Preto, n. 124, ago. 2008.

SILVA, Homero Batista Mateus da. Curso de Direito do Trabalho Aplicado. Vol. 2: Jornadas e pausa. Rio de Janeiro: Elsevier, 2009. 356p. ISBN: 9788535229240.

TRIBUNAL SUPERIOR DO TRABALHO. Livro de súmulas, orientações jurisprudenciais e precedentes normativos. Disponível em: <http://www.tst.jus.br/documents/10157/63003/ Livro-Jurisprud-18-12-2013-igual-IRem.pdf $>$. Acesso em: 02 maio 2013.

\section{NOTAS}

1 NASCIMENTO, Amauri Mascaro. Iniciação ao direito do trabalho. 34. ed. São Paulo: LTr, 2009, p. 279.

2 BEITUM, Silvana Marcelo. Das Horas in Itinere. FADAP Revista Jurídica, Tupã, ex1, n. 3, p. 53-80, dez. 2000, p. 55

3 SILVA, Homero Batista Mateus da. Curso de Direito do Trabalho aplicado. Vol. 2: Jornadas e Pausa. Rio de Janeiro: Elsevier, 2009, ISBN: 9788535229240, p. 13.

4 TRIBUNAL SUPERIOR DO TRABALHO. Livro de súmulas, orientações jurisprudenciais e precedentes normativos. Disponível em: $<$ http://www.tst.jus.br/documents/10157/63003/Livro-Jurisprud-18-122013-igual-IRem.pdf >. Acesso em: 02 maio 2013.

5 BRASIL. Consolidação das Leis do Trabalho. Decreto-Lei no 5452 de $1^{\circ}$ de maio de 1943. Disponível em: <http://www.planalto.gov.br/ccivil 03/ decreto-lei/del5452.htm>. Acesso em 02 maio 2013.

6 SILVA, Fábio Luiz Pereira da; MARTINS, Rafael Tárrega. Horas "in itinere": tratamento no Brasil e na Espanha. Revista Nacional de Direito do Trabalho. Ribeirão Preto, n. 124, p. 31-44, ago. 2008, p. 33.

ALMEIDA, Amador Paes de. CLT comentada. 6. ed. São Paulo: Saraiva, 2009 , p. 76.

8 BEITUM, Silvânia Marcelo. Das Horas “in Itinere”. FADAP Revista Jurídica, Tupã, ex1, n. 3, p. 53-80, dez. 2000, p. 62.

9 RUSSOMANO NETO, Mozart Victor. Horas in itinere: caracterização, trajeto interno, portão de acesso-local demarcação do ponto: breve análise ao entendimento do TST quanto à aplicação analógica da orientação jurisprudencial transitória no 36 da SDI-1. LTr Suplemento Trabalhista, São Paulo, v. 44, n. 103, p. 515-516, 2008, p. 515.

${ }_{10}$ RUSSOMANO NETO, Mozart Victor. Horas in itinere: caracterização, trajeto interno, portão de acesso-local demarcação do ponto: breve análise ao entendimento do TST quanto à aplicação analógica da orientação jurisprudencial transitória $\mathrm{n}^{\mathrm{o}} 36$ da SDI-1. LTr Suplemento Trabalhista, São Paulo, v. 44, n. 103, p. 515-516, 2008, p. 515 .

${ }^{11}$ RUSSOMANO NETO, Mozart Victor. Horas in itinere: caracterização, trajeto interno, portão de acesso-local demarcação do ponto: breve análise ao entendimento do TST quanto à aplicação analógica da orientação jurisprudencial transitória no 36 da SDI-1. LTr Suplemento Trabalhista, São Paulo, v. 44, n. 103, p. 515-516, 2008, p. 516.

12 Revogada por meio da Lei 11/94.

13 ALMEIDA, Ricardo. A construção civil e as horas in itinere. Jornal Trabalhista Consulex, Brasília, v. 28, n. 1387, ago. 2011, p. 11.
14 ALMEIDA, Ricardo. A construção civil e as horas in itinere. Jornal Trabalhista Consulex, Brasília, v. 28, n. 1387, ago. 2011, p. 11.

${ }^{15}$ INSTITUTO DE PESQUISA ECONÔMICA APLICADA. Tempo de deslocamento casa-trabalho no brasil (1992-2009): diferencas entre regiões metropolitanas, níveis de renda e sexo. Disponível em: $<$ http://www.ipea.gov.br/portal/index.php?option=com content\& view=article \&id=16966>. Acesso em: 02 maio 2013.

16 SILVA, Fábio Luiz Pereira da; MARTINS, Rafael Tárrega. Horas "in itinere": tratamento no Brasil e na Espanha. Revista Nacional de Direito do Trabalho, Ribeirão Preto, n. 124, p. 31-44, ago. 2008, p. 35.

17 SILVA, Fábio Luiz Pereira da; MARTINS, Rafael Tárrega. Horas "in itinere": tratamento no Brasil e na Espanha. Revista Nacional de Direito do Trabalho, Ribeirão Preto, n. 124, p. 31-44, ago. 2008, p. 35.

${ }_{18}$ Neste contexto, vale recordar a Súmula 320 do TST: "O fato de o empregador cobrar, parcialmente ou não, importância pelo transporte fornecido, para local de difícil acesso, ou não servido por transporte regular, não afasta o direito à percepção do pagamento das horas in itinere". TRIBUNAL SUPERIOR DO TRABALHO. Livro de súmulas, orientações jurisprudenciais e precedentes normativos. Disponível em: $<$ http://www.tst.jus.br/documents/10157/63003/Livro-Jurisprud-18-122013-igual-IRem.pdf $>$. Acesso em: 02 maio 2013.

${ }^{19}$ SILVA, Fábio Luiz Pereira da; MARTINS, Rafael Tárrega. Horas "in itinere": tratamento no Brasil e na Espanha. Revista Nacional de Direito do Trabalho, Ribeirão Preto, n. 124, p. 31-44, ago. 2008, p. 34

${ }^{20}$ Compreensões doutrinárias e jurisprudenciais que serão pormenorizadas no decorrer do trabalho.

${ }^{21}$ LARA, Waldir de R. Prefixação de horas in itinere e flexibilização de direitos: breves consideraç̃es. Revista do Tribunal Regional do Trabalho da 15 $\underline{\underline{a}}$ Região, Campinas, n. 4, p. 90-92, jan.-jun., p. 91.

22 SILVA, Homero Batista Mateus da. Curso de Direito do Trabalho Aplicado. Vol. 2: Jornadas e Pausa. Rio de Janeiro: Elsevier, 2009. ISBN: 9788535229240. p. 15

${ }^{23}$ LARA, Waldir de R. Prefixação de horas in itinere e flexibilização de direitos: breves considerações. Revista do Tribunal Regional do Trabalho da 15 Região, Campinas, n. 4, p. 90-92, jan.-jun., p. 92.

${ }^{24}$ FRANÇA, Milton de Moura. Renúncia de direito as horas "in itinere" prevista em acordo coletivo: Ineficácia. Genesis: Revista de Direito do Trabalho, Curitiba, v. 4, n. 19, p. 31-32, jul. 1994, p. 31.

${ }^{25}$ SILVA, Fábio Luiz Pereira da; MARTINS, Rafael Tárrega. Horas "in itinere": tratamento no Brasil e na Espanha. Revista Nacional de Direito do Trabalho, Ribeirão Preto, n. 124, p. 31-44, ago. 2008, p. 41. 